(4) The good will of the health care services is paramount in operating any disaster plan.

We thank the following people: Mr A McKibbin, consultant surgeon, Erne Hospital; Major General R J Hodges, Commander Landforces, Northern Ireland; Chief Inspector G G O'Callaghan, Royal Ulster Constabulary, Enniskillen; Miss E Dundas, assistant director of nursing services, Erne Hospital; Mr R Dixon, ambulance officer, Enniskillen; all medical, nursing, and auxiliary staff, Erne Hospital; and the people of Enniskillen.
1 Kennedy TL, Johnston GW. Civilian bomb injuries. Br Med $\mathcal{F}$ 1975;i:382-3. 2 Tucker K, Lettin A. The Tower of London explosion. Br Med $\mathcal{F} 1975$;iii 287-90.

3 Hadden WA, Rutherford WH, Merrett JD. The injuries of terrorist bombing a study of 1532 consecutive patients. Br $\mathcal{F}$ Surg 1978;65:525-31

4 Caro D, Irving M. The Old Bailey bomb explosion. Lancet 1973;i:1433-5.

5 Bradley JEA. Nurse management during the bombing crisis in Birmingham. Nursing Times 1975;71:1186-8.

6 Anonymous. Hospitals and bombs [Editorial]. Injury 1976;3:169-70.

7 Anonymous. Bombs and hospitals [Editorial]. Br Med f 1979;i:506.

8 Holme P. State of emergency: Brighton bomb. Nursing Times 1984;80:16-7.

9 Rutherford WH. Disaster procedures. Br Med f 1975;i:443-5.

10 Patterson C. Explosion: a case study in disaster drills. foumal of Emergency Nursing 1977;3:9-13.

\title{
Prospective randomised study of an orthopaedic geriatric inpatient service
}

\author{
William J Gilchrist, Raymond J Newman, David L Hamblen, Brian O Williams
}

\begin{abstract}
A randomised controlled trial of two management regimens was carried out in women patients over 65 years of age with hip fractures. Ninety seven patients were admitted to a designated orthopaedic geriatric unit and 125 to orthopaedic wards. No difference was observed in mortality, length of stay, or placement of patients between the two groups. More medical conditions were recognised and treated in patients in the orthopaedic geriatric unit group.

It is concluded that designated orthopaedic geriatric units can provide medical care to these patients and should be administered without additional cost.
\end{abstract}

\section{Introduction}

The recent apparent epidemic of hip fractures in elderly women ${ }^{12}$ has led to a greater awareness of the role of the geriatrician in managing these patients in orthopaedic wards. Many centres in the United Kingdom have established formal liaison between the specialties of orthopaedics and geriatrics, and this may be a solution to many of the problems that elderly women patients present.

An orthopaedic geriatric unit was therefore established at Gartnavel General Hospital in February 1983, with 12 existing orthopaedic beds and medical, nursing, and paramedical staff, at no additional cost. After one year's experience of running this service ${ }^{3}$ we designed a prospective, randomised, controlled study to test the efficacy of this approach to managing elderly women patients with proximal femoral fractures.

Department of Geriatric

Medicine, Gartnavel

General Hospital and

University Department of

Orthopaedic Surgery,

Western Infirmary,

Glasgow

William J Gilchrist, MRCP, consultant geriatrician

Raymond J Newman, FRCS, senior lecturer

David L Hamblen, FRCS, professor

Brian O Williams, FRCP,

consultant geriatrician

Correspondence to: Dr W J Gilchrist, Department of

Geriatric Medicine,

Gartnavel General Hospital

Glasgow G12 0YN. directly. The remaining patients were transferred one and a half miles $(21 / 2 \mathrm{~km})$ to the orthopaedic wards in Gartnavel General Hospital for rehabilitation and were entered into the study if they were women over age 65 .

Patients were stratified on the basis of the site of fracture (intracapsular and extracapsular) and randomised to either the orthopaedic geriatric unit or the orthopaedic wards at the time of transfer. A five to four bias was introduced in favour of the orthopaedic wards owing to the larger number of beds there. No patients were excluded from the study after they were transferred.

Patients in the orthopaedic geriatric unit remained under the overall care of the orthopaedic surgical staff. A weekly combined ward round was performed by a geriatrician (consultant or senior registrar), an orthopaedic senior registrar, and the senior ward nurse. A physiotherapist, occupational therapist, and a social worker participated in the case conference that followed. Advice was given on medical problems that arose between ward rounds by consultation with the geriatrician.

The control group had similar nursing cover and access to similar paramedical services but there was no case conference. Referral for any medical problem to the geriatric service was made by letter, and patients in these orthopaedic wards were seen by a different geriatrician from the one on the orthopaedic geriatric unit. Patients did not transfer between the orthopaedic geriatric unit and the orthopaedic wards, and both groups had access to the same hospital facilities.

Information about inpatients was gathered prospectively, and both groups were visited at home three and six months after discharge. Information was collected on a form and stored on microcomputer.

The three outcome indicators discussed in this paper are mortality, length of hospital stay, and placement after discharge. These have been used in other studies. Length of hospital stay is used as an indirect indicator of cost.

We also analysed the medical diagnoses made in each group and the numbers of case records with missing laboratory results. We also report the numbers of patients discharged with abnormal laboratory results or documented clinical findings that ideally should have been further investigated or treated.

Statistical analysis-Mortality, placement of patients, and the numbers of patients with new and "missed" diseases were analysed by $\chi^{2}$ test with Yates's correction. The length of stay was analysed by Wilcoxon's rank sum test. Confidence intervals were calculated for differences in percentages and means. hospitals without facilities for fracture surgery were usually sent back for rehabilitation soon after operation and were excluded from the trial, as were a few patients who made rapid progress and were discharged home 
Results

Between October 1984 and July 1986, 374 women aged over 65 were admitted with proximal femoral fractures. Surgery was performed within 24 hours of admission on $292(78 \%)$ and within 48 hours on 336 $(90 \%)$. One patient only was unfit for surgery. General anaesthesia was used for $359(96 \%)$ patients. Nineteen $(5 \%)$ patients died, $38(10 \%)$ were discharged directly home, and $95(25 \%)$ were returned for rehabilitation to hospitals outside Glasgow. The remaining 222 patients were entered into the trial and randomised either to the orthopaedic geriatric unit (97) or to the orthopaedic wards (125). The length of stay before transfer was $10 \cdot 2$ days for the patients in the orthopaedic geriatric unit and $9 \cdot 8$ days for the control group (difference not significant). The mean age of the patients on the orthopaedic geriatric unit was 82 years and of the control group 80.6 (range 65-98 years), and the difference was not significant.

A total of 183 patients were admitted from the community, and $159(87 \%)$ of these had required support from family members or community services before admission. Table I gives the types of fracture sustained.

Twenty six (21\%) patients in the control group were seen by a geriatrician in hospital (mean total consultation time 20 minutes). Patients in the orthopaedic geriatric unit were seen four times on average by the geriatrician (mean total consultation time 20 minutes).

Although inpatient mortality (table II) was higher in the control group, the difference was not significant (observed mean difference $6.3 \% ; 95 \%$ confidence interval $-0.4 \%$ to $13.0 \%, p=0.06$ ). Ten deaths occurred in each group in the six months after discharge and the observed mean difference in the cumulative death rate was $4 \cdot 1 \%(95 \% \mathrm{CI}-5 \cdot 5 \%$ to $13 \cdot 7 \%, \mathrm{p}>0 \cdot 1)$.

There was no significant difference in the overall mean length of stay between the two groups (observed mean difference 3.7 days; $95 \%$ confidence interval $-15 \cdot 1$ days to $22 \cdot 5$ days, $p>0 \cdot 1$ ) (table III). For patients returning home the difference in the mean length of stay was greater (observed mean difference $10 \cdot 4$ days; $95 \% \mathrm{CI}-9.9$ days to $30 \cdot 7$ days, $\mathrm{p}>0 \cdot 1$ ) but not significant. No difference in the length of stay was noted between the two groups in patients with mini

TABLE I - Types of fractures in study patients

\begin{tabular}{lcr}
\hline & $\begin{array}{c}\text { Orthopaedic } \\
\text { geriatric unit } \\
(\mathrm{n}=97)\end{array}$ & $\begin{array}{c}\text { Orthopaedic } \\
\text { ward (control) } \\
(\mathrm{n}=125)\end{array}$ \\
\hline Intracapsular & $48(49 \%)$ & $69(55 \%)$ \\
Extracapsular & $47(48 \%)$ & $51(41 \%)$ \\
Pathological & $2(2 \%)$ & $4(3 \%)$ \\
Subtrochanteric & 0 & $1(1 \%)$ \\
\hline
\end{tabular}

TABLE II -Cumulative mortality of study patients

\begin{tabular}{lcc}
\hline & $\begin{array}{c}\text { Orthopaedic } \\
\text { geriatric unit } \\
(\mathrm{n}=97)\end{array}$ & $\begin{array}{c}\text { Orthopaedic } \\
\text { ward (control) } \\
(\mathrm{n}=125)\end{array}$ \\
\hline Inpatient & $4(4 \%)$ & $13(10 \%)$ \\
Three months after discharge & $10(10 \%)$ & $18(14 \%)$ \\
Six months after discharge & $14(14 \%)$ & $23(18 \%)$ \\
\hline
\end{tabular}

TABLE III-Length of overall inpatient stay (days). Numbers are means (standard error)

\begin{tabular}{lcc}
\hline & $\begin{array}{c}\text { Orthopaedic } \\
\text { geriatric unit }\end{array}$ & $\begin{array}{c}\text { Orthopaedic } \\
\text { ward (control) }\end{array}$ \\
\hline All patients & $44(5 \cdot 7)$ & $47 \cdot 7(7 \cdot 7)$ \\
& $(\mathrm{n}=97)$ & $(\mathrm{n}=125)$ \\
Patients admitted from home and & $41 \cdot 7(3 \cdot 7)$ & $52 \cdot 1(9 \cdot 7)$ \\
discharged home & $(\mathrm{n}=77)$ & $(\mathrm{n}=94)$ \\
Patients with mini object test score $>19$ & $34 \cdot 8(3 \cdot 3)$ & $56 \cdot 5(15 \cdot 3)$ \\
& $(\mathrm{n}=45)$ & $(\mathrm{n}=56)$ \\
\hline
\end{tabular}

TABLE IV-Placement of patients admitted from home

\begin{tabular}{lcc}
\hline & $\begin{array}{c}\text { Orthopaedic } \\
\text { geriatric unit } \\
(\mathbf{n}=80)\end{array}$ & $\begin{array}{c}\text { Orthopaedic } \\
\text { ward (control) } \\
(\mathbf{n}=103)\end{array}$ \\
\hline Returned home & $60(75 \%)$ & $72(70 \%)$ \\
Residential care (part III) & 0 & 0 \\
Long term geriatric & 7 & 6 \\
Long term psychiatric & 1 & 3 \\
Nursing home & 2 & 4 \\
"Peripheral" hospital & 3 & 5 \\
Died & 3 & 11 \\
Other-for example, surgical, dermatology, & 4 & 2 \\
$\quad$ urology units & & \\
\hline
\end{tabular}

TABLE $\mathrm{V}-$ Unrecognised conditions in patients at discharge

\begin{tabular}{|c|c|c|}
\hline & $\begin{array}{l}\text { Orthopaedic } \\
\text { geriatric unit } \\
\quad(n=5)\end{array}$ & $\begin{array}{l}\text { Orthopaedic ward } \\
(\text { control group }) \\
(n=42)\end{array}$ \\
\hline Vitamin $B_{12}$ deficiency ${ }^{\star}$ & 4 & 12 (49 patients not tested) \\
\hline Iron deficiency anaemia $(<90 \mathrm{~g} / \mathrm{l})$ & & 3 \\
\hline Macrocytic anaemia & & 2 \\
\hline Non-specific anaemia & & 6 \\
\hline Osteomalacia $\nmid$ & & 5 \\
\hline Biliary disease $\ddagger$ & & 3 \\
\hline Diabetes & & 3 \\
\hline Hypothyroidism & 1 & 2(29 patients not tested) \\
\hline Renal failure & & 2 \\
\hline Hyperthyroidism & & 1 \\
\hline Pneumonia $\$$ & & 1 \\
\hline Hepatitis\| & & 1 \\
\hline Recent myocardial infarction & & 1 \\
\hline
\end{tabular}

$\star$ Serum vitamin $B_{12}>15 \%$ below lower limit of reference range. †Low concentrations of serum calcium and phosphorus and raised alkaline phosphatase activity.

$\ddagger$ Raised $\alpha$-glutamyltransferase and alkaline phosphatase activity.

Consolidation seen on chest $x$ ray film with fever.

Rise in all liver enzyme activities and bilirubin concentration.

object test scores of more than 19 out of 30 (observed mean difference 21.7 days; $95 \%$ CI -9.0 days to $52 \cdot 4$ days, $\mathrm{p}>0 \cdot 1)$.

Table IV shows the placement of patients admitted to the Western Infirmary from home. Sixty (75\%) patients returned home from the orthopaedic geriatric unit and $72(69.9 \%)$ from the orthopaedic wards. The observed difference was $5 \cdot 1 \%(95 \% \mathrm{CI}-7 \cdot 9 \%$ to $18 \cdot 1 \%, p>0 \cdot 1)$ and was not significant.

The case records for 88 patients $(91 \%)$ in the orthopaedic geriatric unit and $69(55 \%)$ patients in the control group contained a full set of investigation results. Laboratory results often arrived in the ward after the patient had been discharged from hospital. Also, discharge summaries seldom contained details of abnormal results despite the fact that they were almost always available when the summary was being written.

A greater proportion of patients in the orthopaedic geriatric unit $(71 \%)$ were found to have new medical disorders than those in the control group (55\%) (observed mean difference $=15 \cdot 9 \% ; 95 \%$ CI $3 \cdot 4 \%$ to $28.5 \%, \mathrm{p}<0.025)$. More diagnoses per patient were made in the orthopaedic geriatric unit: new diagnoses were made for $69(71 \%)$ patients and $69(55 \%)$ controls and there were 158 and 121 new diagnoses respectively. Five $(5 \cdot 3 \%)$ patients in the orthopaedic geriatric unit were discharged with "untreated" disease and 33 $(29.5 \%)$ in the control group (observed mean difference $24 \cdot 2 \% ; 95 \%$ CI $14.6 \%$ to $33 \cdot 8 \%, p<0 \cdot 001$ ). The difference was significant and likely to represent an underestimate of the real situation for the control group as many of the tests may not have been performed or the results were missing from the case record. Table V shows the conditions "missed" and these were missed as often in the patients in the control group seen by a geriatrician.

\section{Discussion}

This is the first reported prospective, randomised controlled study of an orthopaedic geriatric inpatient 
service which compares the effect of two methods of management. One type was the formal traditional liaison system, in which the geriatrician's opinion is sought only when the orthopaedic surgeon considers it desirable. The other was the newer concept of shared supervision in an orthopaedic geriatric unit. It has been suggested in Nottingham that there has been a reduction in the mean length of hospital stay since an orthopaedic geriatric unit was established. ${ }^{6}$ Workers in London have supported this view and claim a $46 \%$ saving in bed days for patients aged 60 and over with hip fractures. ${ }^{7}$ It was also suggested that elderly women at a centre in Edinburgh with proximal femoral fractures may be discharged earlier if a combined approach is adopted. ${ }^{8}$ In these studies, however, retrospective control groups were used, patients were preselected for admission to the orthopaedic geriatric unit, and there were changes in the resources of the local geriatric medical service, all of which make it difficult to interpret the results. Because of differences in demography, surgical policy, and the organisation of each of these services we could not compare their results with ours.

A discussion paper from the University of York ${ }^{9}$ describing a small cost-benefit study of collaborative management of a group of such patients suggests that the combined approach might be more expensive and showed no direct benefit to the patient.

A study from the City Hospital, Edinburgh, ${ }^{10}$ also suggests that there may be resource implications in running designated geriatric orthopaedic units. Our service required no increase in staffing or additional transport costs over those for the control group and required no extra funding.

Mortality, length of hospital stay, and placement on discharge were not significantly different between the two groups. One reason may have been changes in the approach of the orthopaedic surgeons to patients in the control group. A greater interest was taken in the medical and social problems of the control group, and towards the end of the study period patient management in this group had considerably changed. Notes from ward rounds and discharge summaries contained more information on the patients' social and medical problems and drug charts generally listed fewer drugs with less potentially toxic interactions. Combined ward rounds on the orthopaedic geriatric unit, which had started before the study, continued throughout the study period and were educational for both. This was unavoidable and resulted from rotation of junior medical staff through the orthopaedic geriatric unit as part of their training.

Another reason for the lack of differences between the groups may be insufficient numbers of patients recruited. Large numbers of patients would be required to clarify this, and we consider a study of such magnitude to be impracticable. Patients may not benefit with respect to length of hospital stay, mortality, or placement on discharge by such an orthopaedic geriatric unit service, and we may have to investigate other performance indicators to detect any advantages.

Many patients in both groups were found to have previously unrecognised medical conditions, and more were recognised per patient in the orthopaedic geriatric unit group. Significantly more conditions with characteristic clinical or laboratory findings remained unrecognised in the control group, and we tried to eliminate subjectivity in this observation by restricting diagnoses to those corroborated by unequivocal datafor example, anaemia:haemoglobin $<90 \mathrm{~g} / \mathrm{l}$. Because the case records were incomplete for almost half of this group there may be more unrecognised disease than we reported. Having the geriatrician available for the control patients did not seem to influence the detection rate of medical conditions nor did it reduce the prevalence of unrecognised conditions at the time of discharge. We consider that the regular review of patients offers a more complete assessment and reduces the likelihood of missing important clinical conditions. It is no more time consuming than a single visit to assess a patient in the orthopaedic wards.

We believe that close cooperation between the geriatrician and orthopaedic surgeon in the care of elderly women with hip fractures results in effective management. Designated orthopaedic geriatric units can provide such care, but we believe that the collaborative approach should be administered within the existing facilities of orthopaedic and geriatric services and additional costs should not be incurred. ${ }^{3}$

We thank the consultant orthopaedic surgeons of both hospitals for permission to include patients under their care and Dr Gordon Murray for his help and advice on the statistical analysis. We also thank the nursing, physiotherapy, and other paramedical staff for their help throughout this project.

1 Boyce WJ, Vessey MP. Rising incidence of fracture of the proximal femur. Lancet 1985; i: 151-2.

2 Bulstrode C. Keeping up with orthopaedic epidemics. Br Med $\mathcal{~ 1 9 8 7 ; 2 9 5 : 5 1 4 . ~}$ 3 Gilchrist WJ, Newman RJ, Hamblen DL, Williams BO. Combined orthopaedic-geriatric care. Lancet 1985;i:349-50.

4 Still CN, Goldschmidt TJ, Mallin R. Mini object test: a new brief clinical assessment for aphasia-apraxia-agnosia. South Med f 1983;76:52-4

5 Hughes AM, Gray RF, Downie D IV. Brief cognitive assessments of the elderly - the mini object test and the Clifton assessment procedures for the elderly. Br f Clin Psychol 1985;3(4):81-3.

6 Boyd RV, Hawthorn J, Wallace WA, Worlock PH, Compton EH. The Nottingham orthogeriatric unit after 1000 admissions. Injury 1983;15: $193-6$.

7 Murphy PJ, Rai GS, Lowy M, Bielawaska. The beneficial effects of joint orthopaedic-geriatric rehabilitation. Age Ageing 1987;16:273-8.

8 Smith DL. The elderly in the convalescent orthopaedic ward: can the geriatrician help? Health Bull 1984;42:36-44.

9 Fordham R, Thompson R, Holmes J, Hodkinson C. A cost-benefit study of geriatric-orthopaedic management of patients with fractured neck of femur. York: University of York Centre for Health Economics, 1986. (Discussion paper 14.)

10 Burley LE, Scorgie RE, Currie CT, Smith RG, Williamson J. The join geriatric orthopaedic service in south Edinburgh: November 1979-Octobe 1980. Health Bull 1984;42:133-40.

(Accepted 22 August 1988)

\section{ANY QUESTIONS}

Do women have lower haemoglobin concentrations than men and if so why?

The mean normal reference value of haemoglobin is usually given as $135 \mathrm{~g} / \mathrm{l}$ for women and $150 \mathrm{~g} / \mathrm{l}$ for men, thus indicating a sex difference of about $10 \%{ }^{1}$ There is some controversy about whether these differences are smaller after the menopause, but even in old age there seems to be a $5-7 \%$ difference between the sexes. ${ }^{23}$

The usual reason given for the difference is the influence of sex hormones on erythropoiesis, and there is good evidence that androgens enhance erythropoiesis whereas oestrogens tend to inhibit it. Menstrual blood loss has also been incriminated, but this may be discounted by the fact that the difference persists after the menopause. Moreover, oral contraceptives, which arrest menstruation, do not as a rule influence the haemoglobin concentration. There is some evidence that women have a lower total red cell volume and higher intravascular plasma volume relative to their body build because of a greater proportion of body fat. Thus the lower haemoglobin concentration may to some extent be a dilutional effect as well. $-S$ M LEWIS, consultant haematologist, London

1 Dacie JV, Lewis SM. Practical haematology. 6th ed. Edinburgh: Churchill Livingstone, 1984:7-10.

2 Kelly A, Munan L. Haematologic profile of natural populations: red cell parameters. Brf Haematol 1977;35:153-60.

Helman N, Rubenstein LS. The effects of age, sex and smoking on erythrocytes and leukocytes. Am $\mathcal{f}$ Clin Pathol 1975;63:35-44. 